\title{
Benign Breast Neoplasm
}

National Cancer Institute

\section{Source}

National Cancer Institute. Benign Breast Neoplasm. NCI Thesaurus. Code C4505.

A non-metastasizing neoplasm arising from the breast parenchyma. 